\title{
Planning Behavior and Perceived Control of Time at Work
}

Citation for published version (APA):

Claessens, B. J. C., van Eerde, W., Rutte, C. G., \& Roe, R. A. (2004). Planning Behavior and Perceived Control of Time at Work. Journal of Organizational Behavior, 25(8), 937-950.

https://doi.org/10.1002/job.292

Document status and date:

Published: 01/01/2004

DOI:

10.1002/job.292

Document Version:

Publisher's PDF, also known as Version of record

\section{Please check the document version of this publication:}

- A submitted manuscript is the version of the article upon submission and before peer-review. There can be important differences between the submitted version and the official published version of record.

People interested in the research are advised to contact the author for the final version of the publication, or visit the DOI to the publisher's website.

- The final author version and the galley proof are versions of the publication after peer review.

- The final published version features the final layout of the paper including the volume, issue and page numbers.

Link to publication

\footnotetext{
General rights rights.

- You may freely distribute the URL identifying the publication in the public portal. please follow below link for the End User Agreement:

www.umlib.nl/taverne-license

Take down policy

If you believe that this document breaches copyright please contact us at:

repository@maastrichtuniversity.nl

providing details and we will investigate your claim.
}

Copyright and moral rights for the publications made accessible in the public portal are retained by the authors and/or other copyright owners and it is a condition of accessing publications that users recognise and abide by the legal requirements associated with these

- Users may download and print one copy of any publication from the public portal for the purpose of private study or research.

- You may not further distribute the material or use it for any profit-making activity or commercial gain

If the publication is distributed under the terms of Article $25 \mathrm{fa}$ of the Dutch Copyright Act, indicated by the "Taverne" license above, 


\title{
Planning behavior and perceived control of time at work
}

\author{
BRIGITTE J. C. CLAESSENS ${ }^{1}{ }^{*}$, WENDELIEN VAN EERDE ${ }^{1}$, \\ CHRISTEL G. RUTTE ${ }^{1}$ AND ROBERT A. ROE ${ }^{2}$ \\ ${ }^{1}$ Technische Universiteit Eindhoven, Eindhoven, The Netherlands \\ ${ }^{2}$ Universiteit Maastricht, Maastricht, The Netherlands
}

Summary This study investigated two mediation models of time management. The first model consisted of parts of Macan's (1994) model. The second model combined this model with Karasek's (1998) Job Demand-Control model. Two sets of self-report questionnaires were collected and were analyzed using structural equation modeling. The first model, in which perceived control of time was hypothesized to fully mediate the relation between planning behavior and work strain, job satisfaction, and job performance, was found to be less adequate than the second model, which added workload and job autonomy as independent variables. Results also indicated that partial, rather than full, mediation of perceived control of time fitted the data best. The study demonstrated the importance of studying both planning behavior and job characteristics, which was not part of past research. Copyright (C) 2004 John Wiley \& Sons, Ltd.

\section{Introduction}

Over the last two decades, many jobs have changed as a consequence of organizational restructuring, technological innovations, and the introduction of new management principles. Professional and managerial jobs have generally witnessed an increase in job scope and autonomy, accompanied by a greater emphasis on speed and timeliness (e.g., Garhammer, 2002). The incumbents of these jobs are typically given substantial discretion in order to deal effectively with complex tasks and tight deadlines (e.g., Tripoli, 1998). Several studies have pointed out the rise in work intensity and time pressure over the last decades as a consequence of these changes (e.g., Endler, Marcrodimitris, \& Kocovski, 2000; de Jonge, 1996; Karasek, 1998). In this context, self-management, especially regarding the temporal dimension of work, has become a critical issue. This is exemplified by the increased demand for time management training in managerial practice, observed by Macan $(1994,1996)$.

Although providers of time management training tend to claim substantial time saving and augmented performance, there is, as yet, little empirical evidence to substantiate these claims. A study by

\footnotetext{
* Correspondence to: Brigitte J. C. Claessens, Subdepartment of Human Performance Management, Department of Technology Management, Technische Universiteit Eindhoven, PO Box 513, 5600 MB Eindhoven, The Netherlands.

E-mail: b.j.c.claessens@tm.tue.nl
} 
Macan (1994) found a weak relationship between participation in time management training and one facet of time management behavior, i.e., 'setting goals and priorities,' also referred to as planning behavior.

Planning behavior can be conceived as part of people's work strategy. A work strategy has been defined as an 'approach to planning and allocating effort across goals, activities, and time periods' (Tripoli, 1998, p. 456). In our definition, the term 'planning behavior' refers to decisions about which tasks to perform, how these tasks should be prioritized, and how to deal with possible distractions, especially when one has to perform several tasks simultaneously. Several studies have been devoted to the effects of planning behavior. Macan (1994) found that planning behavior as such-irrespective of the impact of time management training — had a significant relationship with 'perceived control of time,' which in turn was positively related to job satisfaction and negatively to job-induced and somatic tensions. Perceived control of time thus acted as a mediator in the relationship between planning behavior and these variables. In other studies of planning behavior-usually operationalized as setting goals and priorities-positive relationships were found with self-reported job performance (Davis, 2000; Macan, Shahani, Dipboye, \& Philips, 1990), grade point average (Macan et al., 1990), perceived control of time (Adams \& Jex, 1999; Jex \& Elacqua, 1999; Macan, 1994), job satisfaction (Adams \& Jex, 1999; Davis, 2000; Macan et al., 1990; Macan, 1994), and health (Adams \& Jex, 1999). Furthermore, it was found that planning behavior was negatively related to strain (Jex \& Elacqua, 1999), somatic tension (Davis, 2000), and role ambiguity (Macan et al., 1990).

Studies on so-called 'short-range planning behavior,' i.e., planning in the short run, within the time frame of a week or less, demonstrated a positive relationship to grade point average (Britton \& Tesser, 1991). Also, short-range planning in interaction with achievement striving was positively related to sales performance (Barling, Kelloway, \& Cheung, 1996).

In summary, it appears that planning behavior relates positively to the feeling of being in control of one's time, productivity, job satisfaction, and health, whereas it relates negatively to feelings of strain.

An important limitation of the research carried out thus far is that all studies (except Macan's, 1996, study) have used cross-sectional designs, which makes it impossible to draw conclusions about the direction of these effects. Reversed causation may occur as well (Taris, 2000). Therefore, research with multiple waves is needed to establish the direction of the effects.

The present study is meant to represent a further step in the research on planning behavior by checking earlier findings in a design in which data are gathered in two waves. The point of departure is part of Macan's (1994) model, in which perceived control of time fully mediates the relationship between planning behavior on the one hand, and individual strain, performance, and satisfaction on the other. We will examine the validity of this part of the model and extend it by incorporating two variables derived from Karasek's (1998) work on occupational stress, i.e., workload and job autonomy, which are likely to have an influence on perceived control of time and outcome variables as well.

\section{Planning behavior and perceived control of time}

Planning behavior can be considered a particular way of goal-setting. Goal-setting theory assumes that human action is directed by conscious goals and intentions. However, goals do not have to be in one's conscious awareness all the time during goal-directed action in order for them to regulate action. People make plans to reach sub-goals and focus on them, rather than on the end goal. Continuously focusing on the end goal would distract an individual from taking the actions needed to reach it (Locke \& Latham, 1990). While we prefer to speak of planning behavior, others have used the terms goal-setting and prioritizing (Macan et al., 1990), and short-range planning (Britton \& Tesser, 1991), which are roughly equivalent in meaning. 
The notion of perceived control of time was introduced by Macan et al. (1990). In the process model of time management, which Macan proposed in 1994, three dimensions of time management behavior were distinguished, i.e., setting goals and priorities, mechanics of time management (e.g., making notes and lists), and preference for organization (i.e., working in a systematic fashion). The effects of these behavioral dimensions on outcomes were supposed to be fully mediated by perceived control of time. Macan (1994) derived this supposition from the goal-setting literature. In a sample of 353 part-time students who were also employees of two organizations, Macan indeed found that perceived control of time did mediate between setting goals and priorities on the one hand and job satisfaction, job-induced tensions, and somatic tensions on the other. The mediation effect was not found for performance, however. In a replication study of Macan (1994), carried out in a sample of 525 employees of a variety of organizations who were also part-time students, Jex and Elacqua (1999) found that perceived control of time partially mediated the relations between goal-setting and prioritizing - preference for organization - on the one hand, and strain on the other. In another replication study, involving 522 working adults who were enrolled as part-time students, Adams and Jex (1999) found that perceived control of time mediated between setting goals and priorities, mechanics of time management, and preference for organization on the one hand, and health and job satisfaction on the other. Setting goals and priorities and preference for organization were positively related to perceived control, whereas mechanics of time management were negatively related to perceived control of time. Davis (2000) also conducted a replication study of Macan's (1994) model. In a sample of 54 certified nursing assistants, he found that perceived control of time only acted as a mediator of the relationship between preference for organization and the outcome variables job-related tension, somatic tension, and job satisfaction.

In summary, limited support was found for a mediation effect of perceived control of time, especially with respect to the effects of setting goals and priorities, or planning behavior, and preference for organization (Adams \& Jex, 1999; Davis, 2000; Jex \& Elacqua, 1999). Yet, the evidence is not conclusive and needs further investigation. Moreover, one may argue that time management behavior, and in particular planning behavior, can directly influence performance and job strain, because it may lead to a better temporal fit between personal resources and work demands. Planning may simply help a person to distribute attention and energy more effectively, and thereby help to avoid or reduce delays and overload. Thus, a direct relationship of planning behavior with performance and work strain may exist, in addition to an indirect one, via perceived control of time.

\section{Job characteristics and perceived control of time}

Although perceived control of time is likely to depend on the planning activities of the individual, characteristics of the work setting may play a role as well. In addition, they may directly impinge on the outcome variables. Following Karasek's (1998) Job Demand-Control model one would expect that a person's workload and job autonomy would affect perceived control of time as well as experienced work strain. It seems reasonable to assume that job demands and job control will add to the effects of planning behavior, both on perceived control of time and on the outcome variables.

Job demands can be defined as the psychological stressors that stem from the work environment or workload (Karasek \& Theorell, 1990). In this article, we conceive job demands as workload. Job control can be defined as the extent to which the job provides freedom, independence, and discretion to the employee in scheduling the work and in determining the procedures to be used to carry it out (Karasek $\&$ Theorell, 1990). In the following, we will refer to job control as job autonomy. Both workload and job autonomy are supposed to influence the development of stress (e.g., de Jonge, 1996). The combination of high workload and low job autonomy may produce more stress complaints: the 'strain hypothesis.' In contrast, jobs combining high demands and high control are expected to result in active 
learning behavior: the 'activation hypothesis.' The activation hypothesis states that the combination of high workload and high job autonomy may result in an increase in intrinsic job motivation, learning, and personal growth (Karasek \& Theorell, 1990; Theorell, 2000). Research on occupational stress has provided modest support for the Job Demand-Control model with respect to the strain hypothesis: the interaction between workload and job autonomy (e.g., de Lange et al., 2003; de Jonge \& Kompier, 1997; Dwyer \& Gangster, 1991; Terry \& Jimmieson, 1999). However, most studies have found additive rather than interactive effects of these variables; i.e., high workload and low job autonomy had a significant main effect in relation to stress complaints (e.g., Barnett \& Brennan, 1997; Parkes, Mendham, \& Von Rabenau, 1994). With respect to the activation hypothesis, the results on the association between job characteristics and psychological well-being were inconclusive (Van der Doef \& Maes, 1999, in de Lange et al., 2003). Following past studies on the strain hypothesis, we consider workload and job autonomy as having an additional, rather than interactive effect on outcomes such as work strain. Furthermore, in investigating the activation hypothesis, we focus on job satisfaction as a positive outcome of job characteristics. Here we also consider workload and job autonomy as having an additional effect, rather than an interactive effect. The relation between job conditions and job satisfaction has been established before (e.g., Dormann \& Zapf, 2001).

\section{Models and hypotheses}

In this study we examine two models of planning behavior and its effects over time. The first model, a reduced version of Macan's (1994) model, is depicted in Figure 1.

The model predicts that planning behavior will lead to higher perceived control of time, and that perceived control of time will lead to less work strain, more job satisfaction, and higher job performance. Thus, in accordance with the view of Macan (1994), perceived control of time is supposed to fully mediate the effects of planning behavior on the outcome variables. As we have pointed out before, the assumption of a full mediation effect may be too rigorous. We therefore expect partial mediation to improve the fit of the model, when testing direct links between planning behavior, work strain, job satisfaction, and job performance.

The second model is a modification of the first one. The two work characteristics that were discussed above have been added, i.e., workload and job autonomy. Like Macan's (1994) model, it assumes a full mediation effect of perceived control of time. The second model is depicted in Figure 2. We expect the fit of the model to increase when partial mediation effects are tested, i.e., when direct links are added from planning behavior, workload, and job autonomy to work strain, job satisfaction, and job performance.

In summary, we propose the following hypotheses:

Hypothesis 1a: The model in Figure 1, describing a full mediation of the effects of planning behavior on work strain, job satisfaction, and job performance, produces an adequate fit.

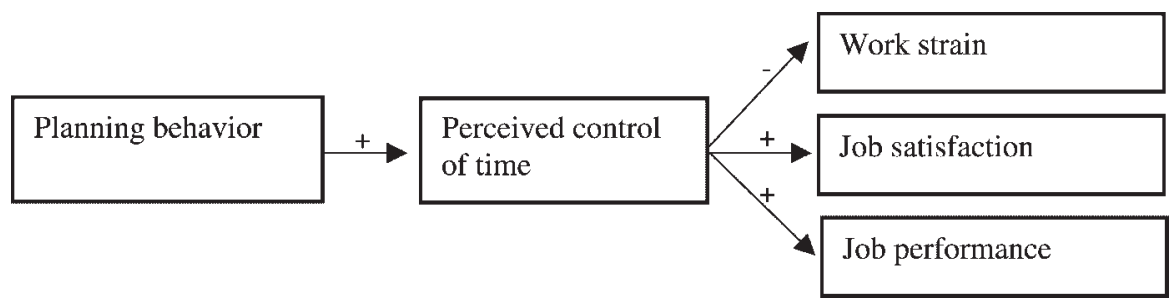

Figure 1. Reduced version of Macan's (1994) full mediation model: the effects of planning behavior (Time 1) on outcome variables (Time 2), mediated by perceived control of time (Time 2) 


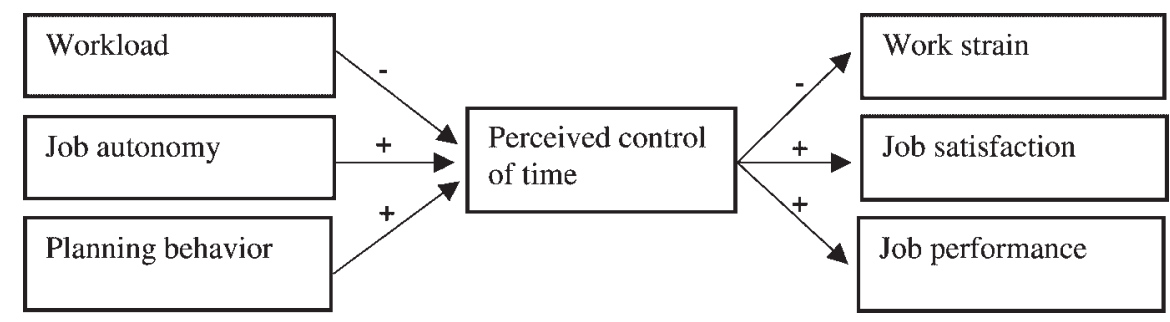

Figure 2. Extended full mediation model: the effect of planning behavior (Time 1) and job characteristics (Time 1) on outcome variables (Time 2), mediated by perceived control of time (Time 2)

Hypothesis 1b: Alternative hypothesis-The fit of the model will improve when mediation is considered to be partial rather than full, that is, when planning behavior is allowed to have direct effects on outcome variables.

Hypothesis 2a: The model in Figure 2, describing a full mediation of the effects of planning behavior, workload, and job autonomy on work strain, job satisfaction, and job performance, produces a better fit than the model in Figure 1.

Hypothesis 2a: Alternative hypothesis-The fit of the model will improve when mediation is considered to be partial rather than full, that is, when planning behavior, workload, and job autonomy are allowed also to have direct effects on outcome variables.

\section{Organizational Context}

\section{The Organization and its Environment}

The employer has approximately 5000 people worldwide as of April 2004. The company has sites in 16 countries around the world, and includes R\&D and manufacturing facilities in the Netherlands and the United States, customer support centers, and state-of-the-art application facilities, technology development centers and training centers in Asia, Europe, and the United States. This organization is currently a highly complex multi-product multi-project organization.

\section{The Departments}

The product development projects of the company are time-paced with generally a 1-year new-product release clock speed. The research and development departments are functionally organized with engineers temporarily assigned to development teams on a project basis. The departments have multiple development projects on hand simultaneously. Power distance between supervisors and employees is generally low in the Netherlands (Javidan \& House, 2001), which is also apparent in this company. The official language in these departments is Dutch, although English is also spoken on a regular basis owing to the large number of foreigners in the company.

\section{Time Frame}

The study was conducted in the first half of 2001 and was completed before September 2001. 


\section{Method}

\section{Sample and procedure}

The location for this research was the Corporate Headquarters of an international company among world leaders in the manufacturing of advanced technology systems for the semiconductor industry, with more than 50 company sites in 16 countries around the world. The company designs, develops, integrates, markets, and services advanced systems used by major global semiconductor manufacturers to create chips that power a wide array of electronic, communications, and information technology products.

$R \& D$ engineers, the participants in this study, worked in one of the major departments of this company in the Netherlands. They were highly educated and were expected to constantly improve on earlier performance. Autonomy and initiative were, as the company believed, the only way to continue to develop ground-breaking products. Employees who wanted to succeed had to show a great deal of initiative and had to provide a substantial degree of individual input. The engineers not only had to deal with high workload and high work pace, but they were also given a large degree of autonomy and flexibility in the execution of their tasks.

One hundred and twenty-four engineers of two research and development departments were recruited to participate in a survey study on how people manage their own work. The departments consisted of a total of 193 engineers and only those who were permanently employed in R\&D were selected for this study.

Ninety-nine engineers returned the first questionnaire and 79 engineers returned the second questionnaire. Nine participants did not return the first survey but did return the second questionnaire, either because they were on holiday at the time of the first survey or simply forgot to return the first questionnaire. Hence, the effective sample size varied from Time 1 to Time 2. Overall, 70 engineers (a 56 per cent response rate) returned two usable questionnaires. Respondents were mainly male ( 80 per cent), with an average age of 33 years. On average, they had worked 4 years within the company, and 2 years in their current job. While the engineers worked on average 8.5 hours a day, 26 of them indicated they also worked during weekends, on average 2.3 hours per weekend. Twelve of them had participated in a time management training program, 3-5 years before this study.

The data were collected in two waves with an interval of 3 months. R\&D projects had a duration of between 3 months and several years. We choose a time lag of 3 months to avoid any influence due to work in different projects during data gathering.

In the original process model (Macan, 1994), perceived control of time mediated between the three time management behaviors and outcome variables concurrently. This would imply that, for instance, planning behavior had an immediate effect on perceived control of time, which in turn immediately effects job performance, job satisfaction, or other outcome variables. In our view, time plays a role, and we consider it unlikely that planning behavior will immediately affect perceived control of time. Instead, we argue for a postponed effect of planning behavior on perceived control of time. Making to-do lists and prioritizing increases the insight into tasks that need to be performed, but only after a while this will lead to the idea that they are under control. So, in the long run, planning enables one to get an overview on the tasks that need to be performed, deadlines, and priorities, which increases the perceived control of time. The immediately measurable effect of planning may even be that it leads to less perceived control of time because it may be confronting to know how much work needs to be done within hours, days, or weeks. However, when control of time is perceived, we expect an immediately measurable effect of perceived control of time on outcome variables such as job performance and job satisfaction. 
All measures were self-administered; the instruction for completion was given on the first page of the questionnaire. To avoid calling attention to time management issues, we included information on the cover page informing respondents that the survey examined opinions about work and personal factors that influence the execution of one's work. All respondents voluntarily completed the two questionnaires and were given company time to respond. The first questionnaire measured planning behavior, experienced workload, and job autonomy. The second questionnaire, which was administered 3 months after the first, covered perceived control of time, job performance, job satisfaction, and work strain. The importance of complete, accurate responses was stressed, and the confidentiality of the responses was assured. Participants were offered a summary of their personal and group results in exchange for their participation.

\section{Measures}

The following scales were covered in the two questionnaires.

Planning behavior was measured with an eight-item scale derived from the subscale 'Setting goals and priorities' of the Time Management Behavior Scale (TMBS; Macan et al., 1990). Based on a previous study, long-term goal-setting items were excluded from the scale (Peeters \& Rutte, 2005). The remaining items referred to planning behavior as we defined it: short-term planning and prioritizing tasks. One item of the TMBS was replaced with a planning behavior item of the Time Management Questionnaire (Britton \& Tesser, 1991). Examples of items included are: 'I set myself short-term goals' and 'I plan my daily work activities.' Responses were made on a five-point scale ranging from 'do not agree at all' (1) to 'completely agree' (5).

Perceived workload was defined as the subjective experience of objective task workload (Van Veldhoven, Meijman, Broersen, \& Fortuin, 1997), and was assessed with an 11-item scale indicating whether a person feels that there is much work to do and whether the work pace is high. Responses were made using four-point scales ranging from 'never' (0) to 'always' (3). Example item: 'Do you need to work fast to finish your work?'

Job autonomy, defined as the degree to which the job provides freedom, independence, and discretion to the employee in scheduling the work and in determining the procedures to be used for carrying it out (Van Veldhoven et al., 1997), was assessed with an 11-item scale, to measure the extent to which a person experiences autonomy on the job. Responses were given on the same four-point scale used for assessing perceived workload. Example item: 'Are you free in executing your work the way you want it?' The perceived workload and job autonomy scales have been validated and are widely used instruments in the Netherlands (Van Veldhoven et al., 2002).

Perceived control of time: six items were used to assess the extent to which individuals believe they can directly affect the way they manage their time. As a pilot study revealed that the Dutch translation ${ }^{1}$ of Macan's original scale produced an unreliable scale, we used two out of five original items, and added four new items. Ratings were made on a five-point scale ranging from 'do not agree at all' (1) to 'completely agree' (5). Factor analysis showed that one item of Macan's scale clearly loaded on another factor and was therefore deleted from the scale. The remaining items were: 'I feel in control of my time,' 'I find it difficult to keep to my schedule because others take me away from my work,' 'I feel that I have my work under control,' 'I feel confident in that I am able to complete my work on time,' and 'I often have little control of what is happening at work.' The explained variance (of the remaining five items) was 41.87 per cent.

\footnotetext{
${ }^{1}$ The items were translated into Dutch and were translated back to the original language by sworn translators.
} 
Job performance was measured by asking respondents to rate their performance in relation to their colleagues (Roe, Zinovieva, Dienes, \& Ten Horn, 2000). Eight statements, for example 'It has been acknowledged that my performance is higher compared to my colleagues' could be rated 'yes, that is true' (1) to 'no, not true' (5). The items were reverse scored so that a higher score indicated a higher job performance. One item was deleted, based on low intercorrelations.

Job satisfaction was measured with the Kunin (1998) faces measure, with five different faces to choose from, ranging from a very happy to a very unhappy face. A high score indicated more job satisfaction.

Work strain was assessed with a 12-item scale (Roe \& Zijlstra, 2000) and indicated people dealing with strain in their job caused by time pressure. Participants responded to each item using a five-point scale ranging from 'do not agree at all' (1) to 'completely agree' (5). Example item: 'I find it hard to relax at the end of a workday.'

\section{Results}

\section{Data analysis}

Descriptive statistics, coefficient alphas, and intercorrelations were inspected. The independent variables were measured at Time 1, while the mediating and dependent variables were measured at Time 2 . We expected a postponed effect of the independent variables on the mediating variable and an immediate effect of the mediating variable on the dependent variables.

First, a full mediation model based on Macan's (1994) model was tested with variables measured over time. Secondly, the same mediation model was tested when allowing partial mediation. Direct effects of planning behavior on work strain, job satisfaction, and performance were tested. Thirdly, an extended full mediation model based on Macan's (1994) model was tested. The model was extended by the inclusion of workload and job autonomy as independent variables. Fourthly, the extended model was tested when allowing partial mediation, i.e. when direct effects of planning behavior, workload, and job autonomy on work strain, job satisfaction, and job performance were added.

We tested the models using structural equation modeling according to LISREL 8.50 (Jöreskog \& Sörbom, 2001). A common method to demonstrate mediation is through multiple regression analysis (Baron \& Kenny, 1986), but structural equation modeling allows for testing the whole model at once with the advantage of including all the variables simultaneously and accounting for all other effects of the variables. This method also reduces the chance of type I error.

We followed the suggestion of Dormann and Zapf (2002), and used all available information and accounted for missing data using the EM algorithm (expected maximalization). The EM algorithm is a general method of finding the maximum-likelihood estimate of the parameters of an underlying distribution from a given data set when the set is incomplete or has missing data due to problems with or limitations of the observation process (Dempster, Laird, \& Rubin, 1977). This technique has been shown to be superior to other missing data strategies such as mean substitution, single regression imputation, pairwise deletion, or listwise deletion (Dormann \& Zapf, 2002).

Our sample consisted of 99 respondents at Time 1 and 79 respondents (of whom nine did not return the Time 1 questionnaire) at Time 2. The EM algorithm was used to replace missing data for the first sample $(n=29)$ at Time 2 and to estimate Time 1 results for the second sample $(n=9)$. Through the application of the EM algorithm, the sample on which the structural equation models were tested consisted of 108 respondents. 
Table 1. Descriptive statistics and intercorrelations among all study variables

\begin{tabular}{|c|c|c|c|c|c|c|c|c|c|c|c|}
\hline & Variable & Range & $M$ & $\mathrm{SD}$ & 1 & 2 & 3 & 4 & 5 & 6 & 7 \\
\hline \multicolumn{12}{|l|}{ Time 1} \\
\hline 1. & Planning behavior & $1-5$ & 3.38 & 0.48 & $(0.72)$ & & & & & & \\
\hline 2. & Workload & $0-3$ & 1.35 & 0.32 & 0.10 & $(0.84)$ & & & & & \\
\hline 3. & Job autonomy & $0-3$ & 2.09 & 0.34 & $0.22 *$ & -0.01 & $(0.74)$ & & & & \\
\hline \multicolumn{12}{|l|}{ Time 2} \\
\hline 4. & Perceived control & $1-5$ & 3.66 & 0.60 & $0.25^{*}$ & -0.20 & $0.29 *$ & $(0.73)$ & & & \\
\hline 5. & Job performance & $1-5$ & 3.73 & 0.48 & $0.33 * *$ & 0.09 & 0.09 & 0.18 & $(0.76)$ & & \\
\hline 6. & Job satisfaction & $1-5$ & 4.08 & 0.67 & $0.30 * *$ & 0.16 & 0.13 & 0.17 & 0.12 & - & \\
\hline 7. & Work strain & $1-5$ & 2.35 & 0.55 & -0.07 & $0.27 *$ & $-0.31 * *$ & $-0.58 * *$ & -0.14 & -0.16 & $(0.85)$ \\
\hline
\end{tabular}

Note: Time $1 n=99$, Time $2 n=70$. Figures in parentheses are alpha reliabilities.

$* p<0.05 ; * * p<0.01$.

To test the extent to which the model fitted the data, the root mean square error of approximation (RMSEA; Brown, \& Cudeck, 1993), the comparative fit index (CFI; Bentler, 1989), and the goodnessof-fit index (GFI; Jöreskog \& Sörbom, 2001) were inspected. Browne and Cudeck (1993) maintained that RMSEA values below 0.05 show a good fit, and values between 0.05 and 0.08 are acceptable. It is customary to regard CFI values higher than 0.90 as indicative of a good fit (Bentler, 1989), although others recently argued that only CFI values of 0.95 and over can be considered to indicate a good fit (Hu \& Bentler, 1999). Modification indices were used to determine whether unspecified paths should be added.

\section{Descriptive statistics}

Descriptive statistics, coefficient alphas, and intercorrelations among planning behavior, job characteristics, and outcome variables at Time 1 and Time 2 are presented in Table 1 . All reliability estimates (coefficient $\alpha \mathrm{s}$ ) were above 0.70 .

\section{Mediation model of planning behavior}

We hypothesized (1a) that a full mediation of the effects of planning behavior on work strain, job satisfaction, and job performance produces an adequate fit. Results showed that the full mediation model did not fit the data $\left(\chi^{2}=17.32\right.$, d.f. $=3, p<0.01$, RMSEA $\left.=0.211, \mathrm{CFI}=0.68, \mathrm{GFI}=0.94\right)$.

Our alternative hypothesis (1b) was that the fit of the model would improve when mediation was considered to be partial rather than full, that is, when planning behavior also had direct effects on outcome variables. The results showed that when partial mediation was allowed, i.e., when direct effects of planning behavior on work strain and on job performance were added, the fit improved $\left(\chi^{2}=6.76\right.$, d.f. $=1, p<0.01, \mathrm{RMSEA}=0.232, \mathrm{CFI}=0.88, \mathrm{GFI}=0.98$ ) but was not yet acceptable.

\section{Extended mediation model of planning behavior}

As an extension of the first model, we included perceived workload and job autonomy as independent variables. The extended model consisted of planning behavior, workload, job autonomy, perceived control of time, and work strain, job satisfaction, and job performance. 


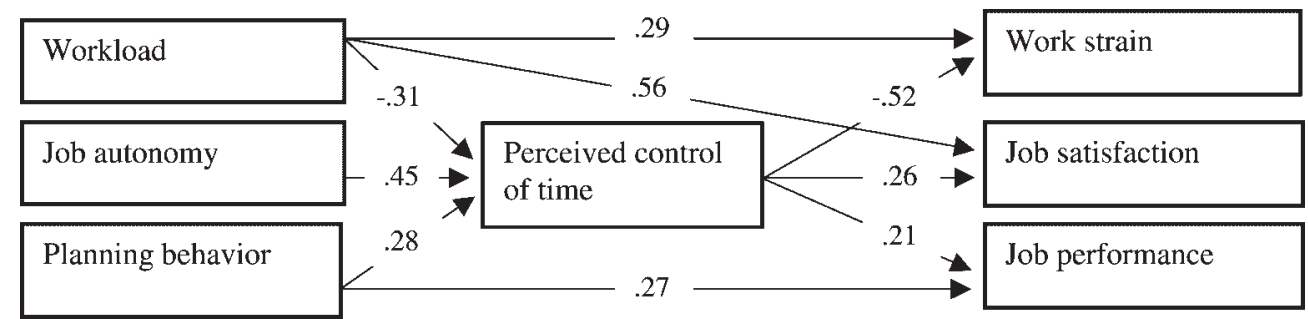

Figure 3. Observed mediation model: the effect of planning behavior (Time 1) and job characteristics (Time 1) on outcome variables (Time 2), mediated by perceived control of time (Time 2) with partial mediation effects

First, we hypothesized (2a) that the extended full mediation model produced a better fit than the full mediation model derived from Macan (1994). Results showed that the fit measures of this full mediation model were slightly better than the original full mediation model (1a), but not convincingly $\left(\chi^{2}=42.67\right.$, d.f. $=14, p<0.01$, RMSEA $\left.=0.138, \mathrm{CFI}=0.74, \mathrm{GFI}=0.90\right)$.

Secondly, our alternative hypothesis (2b) was that when partial mediation was allowed the model's fit would improve. The best-fitting model $^{2}$ was a partial mediation model with direct effects of planning behavior on job performance, workload on work strain, and of workload on job satisfaction. This model, which is depicted in Figure 3, appeared to have an acceptable fit $\left(\chi^{2}=17.42\right.$, d.f. $=11$, $p<0.01, \mathrm{RMSEA}=0.07, \mathrm{CFI}=0.94, \mathrm{GFI}=0.96$ ).

\section{Discussion and Conclusion}

The purpose of this study was first to examine a mediation model based on a process model (Macan, 1994) in which perceived control of time fully mediated between planning behavior and outcome variables over time (Hypothesis 1a) and, secondly, to test an extended mediation model in which perceived control of time fully mediated between job characteristics, planning behavior, and outcome variables over time (Hypothesis 2a). We expected both models to be improved by adding partial mediation (Hypotheses $1 b$ and $2 b$ ).

We were not able to find evidence for a full mediation model as suggested by Macan (1994), so Hypothesis 1a was rejected. Full mediation would imply that planning daily activities and prioritizing them enhances perceived control of time, leading to less strain, more job satisfaction, and higher job performance. This means that by planning activities a cognitive process (perceived control of time) is triggered, which leads to the positive outcomes. However, planning behavior can also affect outcomes directly, because it enables people to structure their activities and schedule them in accordance with available resources and opportunities, which increases the likelihood of completing work as planned and therefore feeling less strained due to work. Allowing partial mediation in this model (Hypothesis 1b) improved the model's fit, but the result was still not satisfying.

The extended full mediation model, which included job characteristics (Hypothesis 2a), did not significantly fit the data, but when partial mediation was allowed the fit greatly improved, confirming Hypothesis 2b. The partial mediation model that best fitted the data allowed direct relations between

\footnotetext{
${ }^{2}$ The results from the mediation analysis $(N=70)$ following Baron and Kenny (1986) were the same as those using the SEM analysis. Only two paths were different: the path from workload to job satisfaction $(N=108)$ was not found in the regression analysis $(N=70)$. Instead we found a path from planning behavior to job satisfaction.
} 
planning behavior and job performance, between workload and work strain, and between workload and job satisfaction. Planning behavior and job autonomy positively affected perceived control of time, whereas workload had a negative effect on perceived control of time. Perceived control of time, in turn, was positively related to job performance and job satisfaction, and negatively to work strain. This suggests that autonomy only has an indirect effect on the outcomes, which means that people with high autonomy experience perceived control of time and therefore feel less strained, more productive, and more satisfied in their work.

There is a partial mediation for workload as well as planning behavior, which means (1) a higher workload leads to less perceived control of time, feeling more strained, less satisfied, and less productive, and (2) planning behavior leads to more control and therefore less strain, more satisfaction, and feeling more productive than others.

Summarizing the above, it was shown that a reduced version of Macan's (1994) model, in which planning behavior was not directly related to outcome variables, but only indirectly through perceived control of time, did not fit our data. Jex and Elacqua (1999) and Davis (2000) were also unable to replicate the full mediation effect, and our study, with data gathered in two waves, once more confirmed their findings. Our findings are also in line with studies by Britton and Tesser (1991), Davis (2000), and Macan et al. (1990) that showed a direct relation between planning behavior and selfreported performance in cross-sectional studies.

The finding that workload had a direct and positive effect on work strain is consistent with past studies (e.g., Karasek, 1998). Workload was also directly and positively related to job satisfaction. This suggests that people do not always experience negative consequences of a heavy workload. Perhaps this is because their work is also perceived as challenging or gives a greater sense of accomplishment upon completion. A positive relation between workload and job satisfaction was also found in a study on general practitioners (GP), who were able to influence the demand-led part of workload themselves (Groenewegen \& Hutten, 1991). In other words, when GPs feel that they can manage their workload to some extent, they are more satisfied with their work even though the workload is high. The same may apply to the R\&D engineers in our sample. This idea corresponds to the activation hypothesis of the Job Demand-Control model, where a combination of high workload and high job autonomy is related to intrinsic job motivation, learning, and personal growth (Karasek \& Theorell, 1990; Theorell, 2000). Future studies should take this possibility into account. Most studies only address the strain hypothesis.

We have shown that perceived control of time is an important variable when studying the effects of planning behavior on the one hand, and the effects of job characteristics on the other. As for the Job Demand-Control model, we have found reasons to suggest that perceived control of time should be included as a mediating variable between job demands and job control, and work strain. Low perceived control of time might be the reason people feel strained due to high workload and/or low job autonomy. This idea deserves further examination in future studies on the Job Demand-Control model.

Concluding, our study stresses the importance of studying job characteristics besides planning behavior, something which previous studies on time management have not addressed. The combination of insights from the Job Demand-Control model and time management perspectives leads to a more adequate view on possible processes involved in work strain, job satisfaction, and performance in highly autonomous jobs.

One limitation of this study is the use of single-source data, which may have introduced a certain degree of method bias. On the other hand, in contrast to most other studies, we have used a design in which data were gathered in two waves, which reduces this bias somewhat because data were collected at least at different moments in time, making reversed causation less likely. The data were collected with an interval of 3 months. The length of the time lag that is needed for the causal variable to influence the effect variable is in general still a point of discussion, since there is little information available (Taris \& Kompier, 2003) and the recommendations concerning the length of this time lag 
tend to be inconsistent (de Lange et al., 2003). The amount of time between waves can be anything from several weeks to more than several decades (Taris, 2000, p. 1). We gathered data with a time lag of 3 months based on the minimum duration of R\&D projects, and although this time lag may not be ideal, at least some time had passed, which reduced the common method bias. Perhaps longer time lags might account for stronger effects.

Another limitation of this study concerns its external validity. The variance of the engineers' scores on workload and job autonomy is quite low. The engineers in this study worked in highly pre-structured and pre-organized jobs, and perhaps in less organized jobs planning may be more strongly related to perceived control of time than in this case. In a more heterogeneous group, we expect to find even stronger relations than in this particular study.

A third limitation of this study is the use of self-reports, especially when assessing job performance. People tend to overestimate their job performance and there may be common source bias with the independent variables. A study including multiple sources of job performance ratings would have been preferable. As a study on the psychometric properties of multi-source performance ratings demonstrated, there was a relatively low correlation (0.35) for the agreement between supervisor and selfratings and also (0.36) between peer and self-ratings (Conway \& Huffcutt, 1997).

Future studies should replicate our study to confirm the positive effects of planning behavior on perceived control of time, as well as on job performance, job satisfaction, and work strain. Also, replicating our study in samples other than R\&D engineers might be interesting. Furthermore, it would be worthwhile to extend the longitudinal study of planning behavior to its relationship with other outcome variables, particularly effectiveness. Effectiveness not only refers to general job performance, but also to dimensions such as the efficiency, time, and quality of work. Effectiveness becomes increasingly important, as people need to improve their work processes continuously and use their time efficiently and effectively. It would be interesting to include effectiveness as judged by people other than themselves (e.g., co-workers and supervisors).

It would certainly be worthwhile to employ different time intervals in future studies, that is, when all variables in the model are measured repeatedly so that the causal relation between variables can be studied. Thus, more information on the suggested postponed effect of perceived control of time can be obtained. Also, measuring the dependent variables at Time 1, mediating at Time 2, and the outcome variables at Time 3 might lead to a better view of the dynamic relationships of the variables.

Finally, future research in this area might also be enriched by applying various research measures, such as daily diaries or experimental methods to study planning behavior and allocation of time. Daily diaries, for instance, could be used to study the actual differences between planned and obtained outcomes of work and the relation with daily work satisfaction. In an experiment, the results of a planning behavior intervention can be studied to see whether or not this leads to perceived control of time.

\section{Acknowledgement}

The authors thank Harry Garst for his statistical advice.

\section{Author biographies}

Brigitte J. C. Claessens is a PhD candidate in the Subdepartment of Human Performance Management of the Technische Universiteit Eindhoven. Her research focuses on individual time management at work. 
Wendelien van Eerde is Assistant Professor in the Subdepartment of Human Performance Management of the Technische Universiteit Eindhoven. Her main research interests are procrastination and motivation at work.

Christel G. Rutte is Full Professor of Organizational Psychology in the Subdepartment of Human Performance Management of the Technische Universiteit Eindhoven. Her main research interests are individual and group performance and time management.

Robert A. Roe is Professor of Organizational Theory and Organizational Behavior at the Universiteit Maastricht. In his current work the emphasis is on patterns of interaction between people in organizations and the roles fulfilled by managers. The stress is on topics such as performance, competence, and knowledge.

\section{References}

Adams, G. A., \& Jex, S. M. (1999). Relationships between time management, control, work-family conflict, and strain. Journal of Occupational Health Psychology, 1, 72-77.

Barling, J., Kelloway, E. K., \& Cheung, D. (1996). Time management and achievement striving interact to predict car sale performance. Journal of Applied Psychology, 81, 821-826.

Barnett, R. C., \& Brennan, R. T. (1997). Change in job conditions, change in psychological distress, and gender: a longitudinal study of dual-earner couples. Journal of Organizational Behavior, 18, 253-274.

Baron, R. M., \& Kenny, D. A. (1986). The moderator-mediator variable distinction in social psychological research: conceptual, strategic, and statistical considerations. Journal of Personality and Social Psychology, 6, $1173-1182$.

Bentler, P. M. (1989). Structural equations program manual. Los Angeles: BMDP Statistical Software.

Britton, B. K., \& Tesser, A. (1991). Effects of time-management practices on college grades. Journal of Educational Psychology, 83, 405-410.

Browne, M. W., \& Cudeck, R. (1993). Alternative ways of assessing model fit. In K. A. Bollen, \& J. S. Long (Eds.), Testing structural equation models (pp. 76-79). London: Sage.

Conway, J. M., \& Huffcutt, A. I. (1997). Psychometric properties of multisource performance ratings: a metaanalysis of subordinate, supervisor, peer, and self-ratings. Human Performance, 10, 331-360.

Davis, M. A. (2000). Time and the nursing home assistant: Relations among time management, perceived control over time, and work-related outcomes. Paper presented at the Academy of Management, Toronto, Canada.

de Jonge, J. (1996). Job autonomy, well-being, and health. Maastricht: University Press.

de Jonge, J., \& Kompier, M. A. J. (1997). A critical examination of the job demand-control-support model from a work psychological perspective. International Journal of Stress Management, 4, 235-258.

de Lange, A. H., Taris, T. W., Kompier, M. A. J., Houtman, I. L. D, \& Bongers, P. M. (2003). 'The very best of the millennium': longitudinal research and the demand-control-(support) model. Journal of Occupational Health Psychology, 8, 282-305.

Dempster, A. P., Laird, N. M., \& Rubin, D. B. (1977). Maximum likelihood from incomplete data via the EM algorithm. Journal of the Royal Statistical Society Series B, 39, 1-38.

Dormann, C., \& Zapf, D. (2001). Job satisfaction: a meta-analysis of stabilities. Journal of Organizational Behavior, 22, 483-504.

Dormann, C., \& Zapf, D. (2002). Social stressors at work, irritation, and depressive symptoms: accounting for unmeasured third variables in a multi-wave study. Journal of Occupational and Organizational Psychology, 75, $33-58$.

Endler, N. S., Macrodimitris, S. D., \& Kocovski, N. L. (2000). Controllability in cognitive and interpersonal tasks: is control good for you? Personality and Individual Differences, 29, 951-962.

Garhammer, M. (2002). Pace of life and enjoyment of life. Journal of Happiness Studies, 3, 217-256.

Groenewegen, P. P. \& Hutten, J. B. F. (1991). Workload and job satisfaction among general practitioners: a review of the literature. Social Science Medicine, 10, 1111-1119. 
Hu, L., \& Bentler, P. M. (1999). Cutoff criteria for fit indexes in covariance structure analysis: conventional criteria versus new alternatives. Structural Equation Modeling, 6, 1-55.

Jex, J. M., \& Elacqua, T. C. (1999). Time management as a moderator of relations between stressors and employee strain. Work and Stress, 13, 182-191.

Jöreskog, K., \& Sörbom, D. (2001). LISREL 8.50: Structural equation modeling (Vol. 1). Chicago: Scientific Software International.

Karasek, R. (1998). Demand/control model: a social, emotional, and physiological approach to stress risk and active behaviour development. In J. M. Stellman, M. McCann, L. Warshaw, \& C. Dufresne (Eds.), Encyclopedia of occupational health and safety (pp. 34.6-34.14). Geneva: International Labor Office.

Karasek, R., \& Theorell, T. (1990). Healthy work: Stress, productivity, and the reconstruction of working life. New York: Basic Books.

Kunin, T. (1998). The construction of a new type of attitude measure. Personal Psychology, 51, 823-824.

Locke, E. A., \& Latham, G. P. (1990). A theory of goal setting and task performance. Englewood Cliffs, NJ: Prentice-Hall.

Macan, T. H. (1994). Time management: test of a process model. Journal of Applied Psychology, 79, 381-391.

Macan, T. H. (1996). Time-management training: effects on time behaviors, attitudes, and job performance. Journal of Psychology, 130, 229-236.

Macan, T. H., Shahani, C., Dipboye, R. L., \& Philips, A. P. (1990). College students' time management: correlations with academic performance and stress. Journal of Educational Psychology, 82, 760-768.

Parkes, K. R., Mendham, C. A., \& von Rabenau, C. (1994). Support and the demands-discretion model of job stress: tests of additive and interactive effects in two samples. Journal of Vocational Behavior, 44, 91-113.

Peeters, M. A. G., \& Rutte, C. G. (2005). Time management behaviour as a moderator for the job demand-control interaction. Journal of Occupational Health Psychology (in press).

Roe, R. A., \& Zijlstra, F. R. H. (2000). Work pressure: results of a conceptual and empirical analysis. In M. Vartiainen, F. Avalone, \& N. Anderson (Eds.), Innovative theories, tools, and practices in work and organizational psychology (pp. 29-46). Stuttgart: Hogrefe \& Huber.

Roe, R. A., Zinovieva, I. L., Dienes, E., \& Ten Horn, L. A. (2000). Test of a model of work motivation in Bulgaria, Hungary and the Netherlands. Applied Psychology: An International Review, 49, 658-687.

Taris, T. W. (2000). A primer in longitudinal data analysis. London: Sage.

Taris, T., \& Kompier, M. (2003). Challenges of longitudinal designs in occupational health psychology. Scandinavian Journal of Work, Environment, and Health, 29, 1-4.

Theorell, T. (2000). Job characteristics in a theoretical and practical health context. In C. L. Cooper (Ed.), Theories of organizational stress (pp. 205-245). Oxford: Oxford University Press.

Tripoli, A. M. (1998). Planning and allocating: strategies for managing priorities in complex jobs. European Journal of Work and Organizational Psychology, 7, 455-476.

Van Veldhoven, M., Meijman, T. F., Broersen, J. P. J., \& Fortuin, R. J. (1997). Handleiding VBBA: Onderzoek naar de beleving van psychosociale arbeidsbelasting en werkstress met behulp van de vragenlijst beleving en beoordeling van arbeid. [VBBA manual: An investigation of perceptions of psychosocial workload and work stress by means of the survey perception and assessment of the work situation.] Amsterdam: SKB.

Van Veldhoven, M., de Jonge, J., Broersen, J. P. J., Kompier, M., \& Meijman, T. (2002). Specific relationships between psychosocial job conditions and job-related stress: a three level approach. Work and Stress, 16, $207-$ 228. 